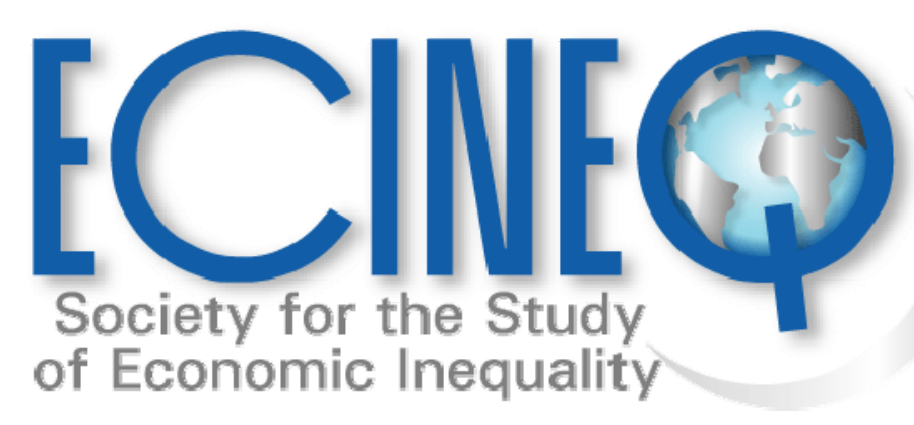

\author{
Working Paper Series
}

Poverty Measurement: The

Development of Different

Approaches and Its Techniques

Celso Nunes 


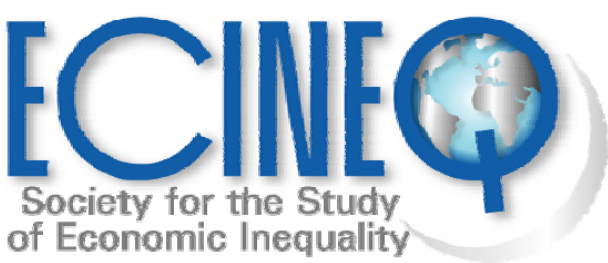

ECINEQ 2008-93

August 2008

www.ecineq.org

\title{
Poverty Measurement: The Development of Different Approaches and Its Techniques
}

\author{
Celso Nunes* \\ Madeira University
}

\begin{abstract}
This work concentrates in the fundamental ideas that constitute the existing theoretical framework of the poverty measurement from the 1960's to the state-of-the-art, with an extended comment on the more relevant issues, the presentation of more influencing approaches and the probable path of future research in Poverty Economics.
\end{abstract}

Key words: Economic Thought, Poverty, Measurement

JEL Classification: B19, B29, B49, I32

* Address of correspondence: Celso Nunes, Departamento de Gestão e Economia, Universidade da Madeira, Caminho da Penteada 9020-105 Funchal Portugal. E-mail: clpnunes@uma.pt . 


\section{The One-variable Approaches}

\subsection{The Absolute Approach}

Mollie Orshansky wrote Counting the Poor (Orshansky, 1965) in which, besides giving continuation to the American empirical studies of the "rediscovery of poverty era", she tackled directly the concepts of poverty and poverty line. She criticizes the measurement indicators of poverty by the Council of Economic Advisors (CEA) as insufficient since the figure expressing an amount of cash income to define families living in poverty must vary for age, family size, geographical area and gender. In a previous work (ibidem, 1963), she describes the evolution towards the desirable definition of equivalent incomes at a poverty level for different family types. It showed how the variable poverty line is derived, the method used and a summary picture of the groups who fell below the line (for 1963 incomes). It also compared the results with the ones from the cruder measure of the CEA. She remits some recognized limitations of the paper, such as the analysis of the situation of unrelated individuals and aged persons living in families headed by younger persons, remitting for subsequent works more refined methods, as the measures based on the relationship of income and consumption. Orshansky also recognizes that it is the purpose of the paper to sketch a profile of 
poverty based on a particular income standard that makes allowance for the different needs of families with varying numbers of adults and children to support. Although recognizing that the standard is arbitrary, she justifies its reasonability on the fact that it is based on the amount of income remaining after allowance for an adequate diet at minimum cost, illustrating it with real numbers. After a brief look at the poverty profile, Orshansky defines the poverty lines based on available standards for food adequacy, chose representative family types, calculated an income-food expenditure relationship and made a farm-non farm adjustment. These procedures resulted in cut-off points that would range from $\$ 1580$ for a single person under age 65 to $\$ 5090$ for a family averaging eight members. Then, she evaluated how adequated is the standard and analyzed the consequences of the variation of the reference point. Orshansky made use of what would later be called the absolute poverty line approach, one where the standard is not determined by the social context.

The World Bank would be a significant booster of the absolute approach, although poverty was basically absent on the World Bank's documents until the late 1960's. Its President in September 1973, McNamara, at the annual general meetings in Nairobi, articulated the concept of absolute poverty. In March 1975 he implicitly defined it as «a condition of life so degrading as to insult human 
dignity». In June of the same year, the World Bank published the book The Assault on World Poverty (1975), which analyses the causes of poverty, examines ways in which it can be alleviated, and outlines programs through which the Bank plans to help. Three important trends have emerged in the debate in defining, measuring and looking at the policy implications of poverty: (1) choosing poverty lines, (2) choosing poverty measures, and (3) making the fine distinction and determining the relationship between inequality and poverty (Ravallion 1996; World Bank 1990; Atkinson 1987; Clark et al. 1981).

Within this objective, a distinction is made between absolute and relative poverty lines. The former has a fixed value over time and space while the latter rises with the average expenditure (Ravallion 1998: 5). When measuring the welfare function, the poverty line is absolute in the space of welfare where poverty comparisons of two individuals are treated in the same way if they are the same level of welfare. Poverty lines are anchored in nutritional requirements for good health and normal activities. In practice, the two most common methods of doing this are through the Food and Energy Intake (FEI) Method and the Cost-ofBasic Needs (CBN) Method. The FEI sets the poverty line by finding the consumption expenditure or income level at which food energy intake is just sufficient to meet pre-determined food energy requirements (Ravallion 1998; 
Ravallion and Lokshin 2003). More importantly, it measures consumption poverty rather than undernutrition, clearly looking for some monetary value of the poverty line at which the "basic needs" are met. The CBN stipulates a consumption bundle that is seen as the adequate level for basic consumption needs proceeded by estimation of costs for each subgroup being compared (Ravallion 1998; Ravallion and Lokshin 2003). There are two components to assess poverty, namely the food and the non-food component. The former is anchored at the nutritional requirements for good health, which most likely does not use monetary poverty line since several bundles of food groups can yield to the same nutritional contents; the latter component creates problems in measurement. The food component of poverty line is divided by some estimate of the budget share devoted to the food. For instance, the average food share in the United States in 1963 was $1 / 3$, making the poverty line three times of the food poverty line (Orshansky 1963).

\subsection{The Relative Approach and Methodological Remarks}

In contrast with the absolute approach, Peter Townsend developed the relative approach as an alternative measure to poverty, breaking with the anterior definitions of poverty. In his 1979 survey (Townsend 1979), he criticizes the 
definitions expressed in terms of some absolute level of minimum needs, though being historically the most influential, as inappropriate and misleading, on the basis that people's needs are conditioned by the society in which they live and to which they belong.

Several problems arise from both methods. The solutions raised are to be conscious of welfare consistency and to treat people with the same living standards equally when measuring poverty. Further, an upper bound for poverty line anchored to certain basic capabilities is also ideal to make poverty measurements comparable over time and space. Ultimately, a maximum admissible poverty line is ideal to best count the poor and to have a fairly good idea of the progress of anti-poverty programs. In updating poverty lines, the literature has developed either the use of the consumer price index or the re-doing of the poverty line itself (Ravallion 1998).

Two different sorts of approaches to poverty lines are the objective and subjective approaches. Objective approaches, in which both absolute and relative poverty lines are included, can be interpreted as attempts to anchor a reference utility level to attainments of certain basic capabilities, of which the most commonly identified relate to the adequacy of consumption for leading a healthy and active life (including participating fully in the society, in the relative 
approach). Let $U$ denote the reference utility level needed to escape poverty (Ravallion 1998). Hence, it is assumed that the household's preferences over all the affordable consumption bundles can be represented by a utility function $U(\mathbf{Q}$, $\boldsymbol{X}$ ) which assigns a single number to each possible $q$, given $x$ (the vector $\mathbf{X}$ refers to the household's characteristics, the vector $\mathbf{Q}$ refers to the quantities consumed of the bundle of goods). The consumer's expenditure function can be described as

$$
z=e(\boldsymbol{P}, \boldsymbol{X}, U)
$$

Consequently, $z$ is the minimum cost to a household with characteristics $\mathbf{X}$ of a level of utility $U$ when facing the price vector $\mathbf{P}$ (when evaluated at the actual utility level, $e(\boldsymbol{P}, \boldsymbol{X}, u)$ is simply the actual total expenditure on consumption, $p \cdot q$, for a utility-maximizing household).

\section{Subjective Approaches}

Another general issue to discuss in poverty analysis is on the survey questionnaires. Different survey questions have been used to find the respondent's opinion on income adequacy. For example, in an early work, Robert Kilpatrick (1973) analyzed time-series data from the United States showing answers to the 
question "What is the smallest amount of money a family of four (husband, wife, and two children) needs each week to get along in this community?" Another example is Dubnoff (1985), which reported a study in which respondents were presented with descriptions of stimulus families possessing various levels of income. The respondents were asked to judge the standard of living for each such family according to a scale where one of the end points was "poor". Analyzing data obtained in Boston in 1983, the author found that the income of the respondent affects the assessment of income adequacy.

The subjective poverty line, developed in the 1970 s, casts doubts over the objectivity of using "basic needs" in poverty measurement including nutritional requirements. If value judgments affect measurements, then the methods are not objective and therefore who is making such value judgments matter, and most likely they are the statisticians and researchers. Certain adjustments have been made to respond to these issues. Rather than dichotomizing their income between needs and luxury, this approach asks the "minimum income question" (MIQ) where individuals or households are asked «at what income level is considered absolutely minimal to survive» or «at what point will their families not be able to make both ends meet» (Ravallion 1998: 21). The responses here are considered as the consumer cost functions at a point of minimal utility (poverty line in utility 
space). Poverty measurement has encountered several problems due to the vagueness of the concept of 'income' in developing societies. Hence, the subjective poverty line has to be reformulated to make the surveys and data more comparable (see Ravallion (1998) for further discussion).

\section{Methodological Issues}

\subsection{Inequality / Poverty Distinction}

The last issue in measurement practices is the convoluted relationship between inequality and income. Besides Rowntree was the first to distinguish (implicitly) poverty from inequality - which is a confusion that we can see even nowadays - before the 1970s there was an assumption of their positive relationship so that income inequality decreases as income growth increases (poverty decline). This is especially visible in the studies made by World Bank in the early 1970s. There was no explicit differentiation between poverty and inequality. Through time, inequality indicators were developed, specifically the Gini coefficient, which measures regions and countries income distribution with 1 
being to most unequal (resources are concentrated on one area) and 0 being the most equal (resources equally distributed across the population). Poverty and inequality therefore developed separate indicators, measurements and conceptual definitions and implications. It shifts the discussion from the single variable measurement of poverty (income) to more multidimensional indicators.

\subsection{Data Gathering Issues}

It is important to note the current practice of international institutions in gathering data to be used in poverty studies. In the $1970 \mathrm{~s}$, the shift from sociological to economic quantitative approach on poverty had a dramatic impact on the study of poverty. The unit of analysis matters, whether it is individual, family, or household, in identifying the progress in growth, designing healthcare programs, and evaluating which government intervention strategies will help in alleviating people from poverty (Atkinson 1985). As observed, systematic household surveys became the basis of econometric studies, looking at consumption, income and eventually other measurable relative variables (e.g. capability, functioning, and deprivation). In the studies on global poverty (Ravallion 2003; Ravallion and Chen 1997, 2001), the use of time-series and cross-country comparisons have used household surveys and statistical records 
conducted by national governments to create data sets for regression analysis. Households are ranked either by consumption or income per person with household size and sample expansion factors being controlled. Although this increased comparability, it has also bred discontentment among scholars because it maintains the monetary approach in measuring poverty (poverty defined by the single variable income). While these studies are measuring individual progress on being poor, data of monetary kind usually pertain to households without being able to measure other resources that affect poverty, such as sanitation, health and clean water. Although the individuals make up the household, it is difficult to ascertain whether the individuals receive these services (Laderchi et al. 2003), i.e., the unit of analysis does not seem to match with what we measure.

\subsection{Poverty Measure Issues}

In choosing poverty measures, most studies employ the head count, or the proportion of the population under poverty (Atkinson 1987). The simple reason is its simplicity (Ravallion 1996). However, this has been criticized (Foster 1984; Sen 1976, 1979) and new alternative poverty measures were developed. For instance, the income gap ratio is increasingly being used, which is defined as the gap between the poverty line and the average income of the poor expressed as a 
proportion of the poverty line. These indices attempt to become neutral to the inequality within the poor, in which most indices focused on alternative poverty gap index (see Foster et al. (1984); Clark et al. (1981); Sen (1976); Watts (1968) for different poverty gap indices).

\subsection{Problems with Some Practices in Poverty Analysis}

Martin Ravallion's (1996) work about measuring and modeling poverty may be considered the last essential one on the Economics of Poverty of the twentieth-century. The paper is an extended comment on some practices in poverty analysis using survey data and a critical description of the state of the art in the end of the century. Although his many comments go mainly to some practices in the analysis of poverty in the studies that use data, he does not ignore the fundamental issues, discussing some options taken by the investigators that influence the path to a better comprehension and explanation of the poverty phenomena. The measurement issues are commented while some arguments are presented to support several methodological proposals - as the arguments for and against the discontinuous variation registered by some measures around the poverty line and the implications of that discontinuity for the policy against poverty - as well as while conceptual and empirical problems raised by the 
traditional approach are presented - as the sensitivity to the distribution of the poverty measures, the consequences of the poverty lines for the policy (namely the perverse consequences of the relative poverty lines) and still while some own proposals - as the favorable argument for social indicators and the presentation of the necessary ingredients for a credible approach to poverty measurement. These include real expenditure per single adult on market goods, non-income indicators such as access to non-market goods, indicators of intra-household distributions such as child nutritional status, and indicators of personal characteristics which impose constraints on the ability of an individual such as physical handicap (ibidem, 1996). His comments go still far away to the modeling of poverty. He discusses what can be learned from a regression of poverty, the links between income poverty and human development, poverty dynamics and the economic geography of poverty. Data-related issues are also commented, with a critic description of what is done currently and several proposals of what should be done for a better performance, and how errors should be dealt with. Conceptual and empirical problems raised by the so called monetary approach should be struggled with complementary measures that grasp what is not grasped (non market goods and heterogeneous distribution inside the households are some examples). Another fundamental conclusion is that the exit from poverty may be 
very dependent on individual characteristics, the household and the environment (community).

\subsection{Poverty Lines Plausibility}

Poverty lines are often drawn to assess whether growth has affected the number of people living in poverty and also frequently chosen based on its objective, whether it aims to improve particular social welfare functions or to reduce poverty (Atkinson 1998; Pritchett 2006; Ravallion 1998), but some authors put this in question and even the poverty line itself, as Angus Deaton points out: «For policy evaluation, the social welfare function is all that is required to measure welfare, including an appropriate treatment of poverty. While it is possible - and in my view desirable - to give greater weight to the needs of the poorest, I see few advantages in trying to set a sharp line, below which people count and above which they do not. Poverty lines and poverty counts make good headlines, and are an inevitable part of the policy debate, but they should not be used in policy evaluation. Perhaps the best poverty line is an infinite one; everyone is poor, but some a good deal more so that others, and the poorer they are the greater weight they should get in measuring welfare and in policy evaluation» (Deaton, 1997: 141). 


\section{The Capability Approach}

The critique over one-dimensional indices is useful since most poverty indicators have been in one way or another associated with "income" indicators. Sen (1985) forcefully argues for the inclusion of "non-income" indicators such as social indicators like life expectancy, literacy and infant mortality. This is the basis of the so-called human development paradigm (HDI). International institutions, primarily the United Nations Development Program (UNDP), have adopted such practice in poverty measurements. The turn towards multidimensional approaches in poverty analysis led to the development of multidimensional measurements of poverty, inequality and standards of living. Amartya Sen's capability approach has become particularly relevant in the poverty discourse, having been serious in criticizing the one-dimensional consumption/income-based measurement of poverty and inequality. Consequently, the capability approach of Amartya Sen stands out as the foundation of the HDI. He forcefully argued for an absolutist core in judging the quality of life of peoples, which is the capability to achieve various "beings and doings". Poverty is a function of the absence of capability:

«Capability refers to a person's or group's freedom to promote or achieve valuable functionings. It represents the various combinations of functionings (beings and doings) 
that the person can achieve. Capability, thus, is a set of vectors of functioning, reflecting the person's freedom to lead one type of life or another... to choose from possible livings. It is concerned with the real opportunity that we have to accomplish what we value. It has intrinsic as well as instrumental value». (Alkire 2002: 6, emphasis in original).

In his work on measuring poverty (Sen 1979), he sees this as a descriptive exercise rather than an ethical one as often perceived. Here, Sen establishes equilibrium between the absolute and relative approaches, develops non-income indicators to identify the poor (which includes the direct or the income method), and aggregates the poverty characteristics into one overall measure. This article likewise recognizes (1) the difficulties in the conversion of families into equivalent adults, (2) the violation of elementary characteristics by the standard measures of poverty (such as the head-count and the income gap ratio), and finally (3) shows intuitively how the "axiomatization" of the aggregation exercise leads to a poverty measure that is a function of the head-count ratio, the income-gap ratio and the Gini coefficient, and how the axioms used for deriving this poverty measure can be varied. His absolutist approach to poverty was realized in his 1983 article Poor, Relatively Speaking. Poverty is relative in the spaces of income and resources - it largely depends on how much another individual obtains - while it is absolute in the spaces of capability or functioning - it has to do more with the 
inability of the individual to be or to do certain things (Qizilbash 2002: 758; Sen $1983,1985)$.

\section{Multidimensional Approaches}

Even though poverty is one of the most recognizable and lasting conditions known to humankind, it is a very complex concept to comprehend. Some researchers perceive this complexity as an adaptation to the condition of poverty, while others interpret it as a reaction to the strain of being poor. Nowadays definitions are plentiful and may be classified as relating to either lack of income or lower status. While poverty has been seen as an economic concept for a long time, many factors contribute to the development of the concept, including political, economic, social, and cultural forces.

\subsection{The Fuzzy Set Theory-Based Contributions}

Although the poor/non-poor dichotomy has been widely criticized, the capability approach failed to fully develop poverty indicators that are measurable. As a response, a new approach of the poverty measurement starts to be considered 
as an alternative: the fuzzy approach. This innovation in the study of poverty measurement consists in the application of some concepts developed in the Fuzzy Set Theory, a mathematical theory developed since the 1960s, mainly by Lotfi Zadeh and Marian Stachowicz. The fundamental novelty of this theory consists on the admittance that there are sets in which there are not only elements that verify the dichotomy "it belongs or it does not belong" to the set. The usually incomebased analyses raised important problems: bias - due to the undervaluation of the answers - and subjectivity - due to the complexity in the specification of the concept of income. Although the poverty line is understood by many authors as a continuum, there is still the distinction between poverty and not poverty across a simple line. Hence, a conceptual tool that would be useful is one that looks at individuals in poverty not in static form but in a gradual transition towards nonpoor.

The first fuzzy set theoretic measurement of poverty is from Cerioli and Zani (1990), where a cut-off point is established upon which an individual is considered non-poor, definitely poor, and relatively poor. The set of poor is people $A$, where $\mu_{A}$ belongs to the $(0,1)$ interval. An individual who is definitely poor correspond to $\mu_{A}=1$ while someone who is definitely not poor to $\mu_{A}=0$. Someone who is relatively poor, that is, an individual to some degree is poor, has 
$0<\mu_{A}<1$. Cerioli and Zani developed an ordinal method of scoring to rank the level of deprivation. ${ }^{1}$ Using the rank order score $P$ with poverty dimension $j$, we can come up with $P_{j}^{\prime}$ for the score of someone who is definitely poor while $P_{j}^{\prime \prime}$ is the score of someone who is definitely non-poor. $P_{i j}$ gives the score of the individual $i$ with dimension $j$. Individual $i$ 's degree of membership of the set of poor in dimension $j$ is written $z_{i j}$. Considering the equation

$$
\mathrm{Z}_{\mathrm{ij}}=\left(\mathrm{P}_{\mathrm{j}}^{\prime \prime}-\mathrm{P}_{\mathrm{ij}}\right) /\left(\mathrm{P}_{\mathrm{j}}^{\prime \prime}-\mathrm{P}_{\mathrm{j}}^{\prime}\right),
$$

$\mu_{\mathrm{A}}$, the degree to which someone belongs to the set of poor, is a weighted average of the $\mathrm{z}_{\mathrm{ij}}$ (Qizilbash 2002).

A totally fuzzy and relative (TFR) approach was proposed by Chelli and Lemmi (1995). This approach has the advantage of going beyond the arbitrariness of the cutoff point in Cerioli and Zani (1990). Nonetheless, the TFR indices raise aggregation, comparison and interpretation problems, once that its values have not an inherent meaning. Another disadvantage is the arbitrariness of the weighting used in the aggregation of the information supplied by the diverse indicators.

\footnotetext{
${ }^{1}$ The discussion here is based on (Qizilbash, 2002).
} 


\subsection{The Human Development Index}

The shift to the multidimensional conceptualization of poverty raises two questions. First, what is the goal of poverty measurement with respect to quality of life? Second, how can developing new poverty measurements address human poverty and inequality? As such, the Millennium Development Goals (MDGs) of the United Nations was conceptualized based on the link between poverty and quality of life. Consistently with the capability approach, the MDG measures poverty not simply to count the poor people per se, but also to identify which sectors are to be targeted by redistribution policies and poverty-reduction measures. In effect, human poverty is conceptualized and measured to solve the discrepancy in the quality of life across countries and regions. This significantly contributes in reevaluating the understanding of poverty not just as a welfare function but also as a policy issue.

The (HDI) is a social indicator of poverty has gained significant momentum over the years. Developed by Mahbub ul Haq, it has since been used by the United Nations Development Program in order to measure well-being in correlation to traditional per-capita income measures forwarded by the World Bank in the year 1948. Technically, the HDI is defined as «the arithmetic average of a country's achievements in three basic dimensions of human development» 
(Cashin et al. 2001). The three basic dimensions of human development include living standards (GDP per capita in USD at purchasing power parity), educational attainment (adult literacy rate and literacy at each level of education), and longevity (life expectancy at birth). The HDI ranges from a value of zero (low HD) to a value of one (high HD).

The popularity of the HDI as a social indicator of poverty that supplements the official indicators is due to the fact that the data used to compile the HDI and the methodology applied to arrive at the values are uniform across the board. This allows for adequate comparison of poverty among various countries (something that was originally difficult given that the there are no standard indicators of poverty prescribed internationally). It implies that there is greater accuracy in reading the trends in poverty globally, regionally and even within countries. Moreover, it makes this index easily accessible to many countries albeit their differing official sets of indicators, and easily applicable to any unit of analysis (country, region, or city units). This is why most countries through UNDP have been able to make significant assessment over the causes of poverty within countries and which sectors and regions require more and certain types of redistributive policies. 
The HDI supplements traditional measures of poverty through an expansion of a per-capita income threshold into the realm of poverty indicators measuring well-being - a more holistic and realistic perspective of the tangible manifestations of poverty using social indicators that contribute to the degree of deprivation in poor countries. These capacities of the HDI as a poverty indicator is supported by its consistency to even the more conventional measures; it has a high correlation with other more conventional poverty indicators like the Gini Coefficient, the per capita income, the income threshold (the World Bank measure of \$1 per day), and Food and Agriculture Organization's (FAO) measure of undernourished population. While it is consistent with these measures, it does not imply that the HDI may be foregone in favor of conventional, income-based indicators in their own merit as the HDI will yield the same result. In fact, a clear case showing the utility of HDI as a social indicator of poverty is the comparison between the ranking in poverty if we use per-capita income and HDI.

New correlations were found through the development of HDI as a poverty indicator. Some of the implications offered by the International Monetary Fund (IMF) on the surface conclusions that may be surmised from HDI data over the years include a strong correlation between the improvement of the HDI and sound macroeconomic policies, or fostered per capita GDP growth. However, a 
country with an increase in GDP and possibly greater economic efficiency does not explicitly relate to a reduction of the incidence of real poverty among marginalized sectors. This efficient allocation of resources and efficient economy may not be socially-preferred still as a result of equity issues as regards the distribution of the increase in GDP among those whom poverty is evident.

This presents us with some weaknesses as regards the extent of capacity of the HDI as a poverty indicator and as a success benchmark for poverty alleviation. Following from the conclusion of trends in HDI data that show how an increase in GDP implies an improvement in the HDI, and the possibility that an increase in GDP and its distribution may not be targeted towards the poor, this tells us that an improvement on HDI does not assure that benefits accrue to the poor toward the end of poverty elimination or alleviation. This, alongside the fact that the HDI is an arithmetic average, tells us that the HDI rather ambiguously describes the extent of poverty, its nature, and the subsequent effects of poverty-reduction policy.

\subsection{An Approach Based on Functioning Failures}

François Bourguignon is one of the authors who focused on the redistributive properties of poverty and the inclusion of various dimensions of 
deprivation in poverty measurement. In the paper with Satya Chakravatry (Bourguignon and Chakravatry 2003), he emphasized the inability of "minimally acceptable" levels of different monetary and non-monetary attributes necessary to subsistence living to capture the multidimensionality of poverty. They used functioning failures in terms of shortfalls from threshold levels of attributes as the indicator for poverty and deprivation. This makes poverty an 'absolute' type, which means that an individual is considered poor if his index of aggregate wellbeing falls below some poverty line. The aggregate of individual attributes may include income, health, education, etc. The article develops poverty index postulates independent of the non-poor attribute quantities and also calculates for the contribution of the subgroup poverty levels to the overall population thereby allowing us to identify which sets of groups are most afflicted by poverty. They attempt to include additive multidimensional poverty indices to complement the individual poverty function in a two-dimension case. To show the reliability and validity of these measurements, Bourguignon and Chakravatry tested it in the rural Brazilian case with two dimensions of poverty, namely income and educational attainment, using the household surveys of 1981 and 1987. The research design was applied in the rural population since this is where poverty is mostly concentrated and only to the adult population to exclude children still going to school in the final education attainment indicator. Their findings suggest 
that there was more poverty in 1987 than in 1981 in the income dimension; it is also the case that income losses may have been worse for people with low income and low education. Moreover, the increase in income poverty is coupled with a drop in educational levels (p. 45). On the other hand, Bourguignon and Fields (1990) showed that optimum allocations can be either of three types: (1) allocating the budget to the poorest of the poor who need the resources most; (2) allocating all the budget to the richest of the poor so as to increase the number of people escaping from poverty; or (3) making a mixed allocation of resources with some part going to the poorest of the poor and some part to the richest of the poor. This result is further explored in their 1997 paper Discontinuous Losses from Poverty. It first considers two budget allocation issues, namely the specification of the loss-from-poverty function and the optimal allocation of an antipoverty budget. It justifies why a poverty-line-discontinuous (PLD) poverty function is the appropriate analytical tool for poverty measurement on budget allocation and this has been integrated in the 'generalized $\mathrm{P}$ measure'. The resulting equation is as follows:

$$
\mathrm{P}_{\alpha, \delta}=1 / \underset{\mathrm{i}=1}{\mathrm{~N}} \underset{\sum}{\mathrm{q}}\left\{\delta+\left[\left(\mathrm{z}-\mathrm{y}_{\mathrm{i}}\right) / \mathrm{z}\right]^{\alpha}\right\}=\delta \cdot \mathrm{H}+\mathrm{P}_{\alpha} .
$$

This poverty measurement has been carried through another study. It was a group of scholars looking at poverty and income distribution at the time of policy 
adjustments. Bourguignon, de Melo and Morrisson (1991) drew policy lessons from the case studies of Chile, Cote d'Ivoire, Ecuador, Malaysia, Morocco and Indonesia on the possibility of easing poverty and income distribution during economic transitions or reform period. This paper applies the indicators Bourguignon developed throughout his career and use them to assess the impact of structural adjustments to poverty and inequality. The debate is whether the poor would have fared worse or not had the adjustments not taken place; the paper considers the enormous difficulty in identifying the poor and attributing changes in their well being to the government policy. It raises an essential issue and justification in using case studies: that poverty measurement is inherently problematic and high levels of abstractions need to be complemented by in-depth studies looking at institutional contexts, conflicts of interests and power among social forces, and the role of human actions/strategic choices in the overall antipoverty effort. Hence, even if the paper uses distribution income and welfare functions to analyze poverty, the case studies weighed more in explaining the different outcomes of the same policy. 


\subsection{The Latent Class Model}

Pasi Moisio contributed in multidimensional measurement of poverty by formalizing it in the Latent Class Model (LCM). In response to one-dimensional poverty measurements (low income, poor living conditions, low consumption, subjective feeling of poverty), new poverty studies employed indicators with direct and indirect measurements (e.g. Atkinson et al. (2002)). The studies by Moisio (2004) and Moisio and Breen (2004) combine the Generalisability Theory and Classical Test Theory to apply measurements in taking into account social stratification and exclusion. An LCM is defined as «a measurement model relating the categorical latent variable to the discrete scores or categories of manifest variables» (Lazarsfeld and Henry 1968: 15-17, in Moisio 2004: 709). The LCM is referred to as a log-linear model with a latent variable. It is a statistical model, which means that relationships between latent and manifest variables are accounted for by probabilistic relationships, thus also allowing for the estimation of error in the model. The two equations are as follows:

$$
\begin{array}{ll}
\mathrm{X}_{\mathrm{i}}=\mathrm{T}_{\mathrm{i}}+\mathrm{E}_{\mathrm{i}} & \text { (Classical theory) } \\
\mathrm{X}_{\mathrm{pi}}=\mu_{\mathrm{p}}+\mu_{\mathrm{i}}+\mu_{\mathrm{pi}, \mathrm{e}} & \text { (G Theory) }
\end{array}
$$

The observed value $\mathrm{X}$ is expressed in the classical measurement theory as the sum of the true value $T_{i}$ and measurement error $E_{i}$. In $G$ theory, the score of a person is 
expressed as the linear model of person effect $\mu_{\mathrm{p}}$, indicator effect $\mu_{\mathrm{i}}$, and their inter action effect $\mu_{\mathrm{pi}, \mathrm{e}}$. However, this does not reflect the multidimensional measurement of poverty; therefore, the value of $T$ can be replaced by the latent variable $\eta$ (eta). This is formally introduced as:

$$
\begin{aligned}
& X^{A}{ }_{i}=\eta_{i}+e^{A}{ }_{i} \\
& \cdots \\
& X^{N}{ }_{i}=\eta_{i}+e^{N}{ }_{i}
\end{aligned}
$$

where the observed score $X^{N}{ }_{i}$ of a person $i$ in the variable $N$ is presented as the sum of the latent score $\eta_{i}$ and the measurement error $e^{N}{ }_{i}$ of the person $i$ in the variable $N$. The equation presents the observed value of each measurement in the multidimensional measurement set as a simple sum of the latent (true) score and measurement error, like the classical theory, but it accepts multiple sources of error, just like the G theory.

Since each effect parameter can have error term, there are three estimates describing measurement error. However, the interaction effect itself is usually understood as one source of measurement error, because its coefficient indicates how differently indicators measure different persons. In other words, the interaction parameter describes the measurement error that is caused (usually) by 
people interpreting the measurement device differently (Moisio 2004: 707). In modeling the poverty dynamics in ten European countries (Moisio and Breen 2004) the latent model was also utilized where categorical rather than continuous variables were used. In this way, relative differences in wealth and other resources are assumed to cause an absolute difference in the capability to function or attain some minimum acceptable way of living in the society. The conclusions to draw are as follows: (1) correcting measurement errors through the LCM affects conclusions within and across countries especially the variation in poverty rates; (2) the poor (defined as relative income poverty) is badly identified more so inaccurately measured as non-poor; and (3) the LCM can be used to test whether the indicators correctly measure the corresponding latent variable. In these two studies, poverty measurement is treated as a way to correct the welfare function approach to poverty.

\section{Other Approaches}

This section discusses the specific contributions of various scholars in poverty measurement and the relations of poverty to other dimensions of 
economic well-being. It surveys the work of Deitz, Biewen, Zheng, Kakwani and Hill, and Lever et al..

\subsection{The Usage of Experiments}

Richard Deitz contributes in poverty measurement by using an experiment in income redistribution. In a simulation exercise, Deitz (1996) asked 10 people to give $\$ 1$ each with the idea that one of them will be the beneficiary of the collected sum of money. The challenge is for the group to come up with a collective (unanimous) decision as to whom the money will go. Two assumptions were further made: the beneficiary may not share the money with anyone else and the money must be solely and completely used by the person. In making the decision, the group can decide in whatever way they want except for random choice (such as drawing straws). The results raise several issues in policy making. These include determining who "deserves" the money, "how will the money be spent",

and who "needs" it. In effect, the experiment has reflected several real world questions, such as whether the taxes in a welfare state are redistributed based on who needs it most, whether the poverty programs consider the ways by which beneficiaries spend the money, and how the poor is defined and counted by the government (poverty measures). 


\subsection{A Discrete Semiparametric Methodology}

Martin Biewen (2001) develops a "discrete variant of semiparametric methodology of DiNardo, Fortin and Limieux (1996) or DFL to measure the effects of socioeconomic variables on income distribution. Unlike DFL which used reweighed kernel-density estimates of income distribution, the paper makes a discrete modification by using directly the given unsmoothed income distribution extended to multinomial variables. Population measure is defined as:

$$
I(t)=\sum_{n=1}^{N} g\left(y_{n}\right) P(n \mid t)
$$

where $t$ is the point of time when the population is surveyed, and $P(n \mid t)$ is the weight of individual $n$, for example, $P(n \mid t)=1 / \mathrm{N}$, and $\mathrm{g}(\cdot)$ is the function characterizing the population measure. For example, $I(t)$ denotes mean income, if $g\left(y_{n}\right)=y_{n}$ or the variance, if $g\left(y_{n}\right)=\left(y_{n}-\sum^{\mathrm{N}}{ }_{\mathrm{n}=1} y_{n} P(n \mid t)\right)^{2}$.

From this definition, it is expressed in terms of discrete outcomes and applied the probit model.

$$
P\left(x^{j} \mid z\right)=\Phi\left(\kappa_{\mathrm{j}}-z^{\prime} \beta\right)-\Phi\left(\kappa_{\mathrm{j}-1}-z^{\prime} \beta\right)
$$

with estimated parameters $\beta$ and $\mathrm{\kappa}_{\mathrm{j}}, \mathrm{j}=0 \ldots J$ for data from $\mathrm{t} E\left\{\mathrm{t}_{\mathrm{x}}, \mathrm{t}_{\mathrm{y}}\right\}$ and $\Phi(\cdot)$ the standard normal distribution function. 
The model is tested empirically in the German transition process case. Using cross-sectional data from the German Socio-Economic Panel (GSOEP), the index developed have two specifications. In the first one, the prominent variable $\mathrm{x}$ is the number of working women in the household (full-time or part-time employed); in the second, it is the corresponding number of unemployed. The vector of other characteristics, $z$ (which is used to estimate the Probit models), consists of variables characterizing the age, education, and employment structure of the household of the individual under consideration. The results of the model suggest the following trends: declining participation rates of women, rising unemployment. and increasing dispersion in the income structure contributed considerably to the increase in income inequality in East Germany from 1990 to 1995 (Biewen 2001: 189).

\subsection{The Incidence of Distribution of Resources}

In the study of Zheng (2001), he points out the shift in poverty measurement not simply considering the counting of the poor but also the incidence of distribution of resources among the poor. In developing appropriate statistical inferences for poverty measurement with relative poverty lines, the paper uses a class of decomposable poverty measures together with percentages of 
mean income and percentages of quantiles as indices. The decomposable poverty measure starts with a continuous form:

$$
P(F ; z)=\int_{0}^{\infty} p(x, z) \mathrm{d} F(x),
$$

where $p(x, z)$ is the individual poverty deprivation function and is continuous in both $x$ and $z$ with $p(x, z)=0$ for $x>z, \delta p(x, z) / \delta x \leq 0$ and $\delta^{2} p(x, z) / \delta x^{2} \geq 0$ over $(0, z)$. We also assume that $p x(x, z) \equiv \delta p(x, z) / \delta x$ is bounded and that $p_{z}(x, z) \equiv$ $\delta p(x, z) / \delta z-$ the increase in $p(x, z)$ when the poverty line $z$ is increased by an infinitesimal amount - exists and is uniformly continuous over $(0, \infty)$. Consequently, we may reasonably assume that $a \equiv \int_{0}^{z} p_{z}(x, z) \mathrm{d} F(x)=\delta P(F, z) / \delta z$ - the increase in $P(F, z)$ when the poverty line $z$ is increased - exists and is finite.

From this decomposable property, two types of relative poverty lines are developed: mean poverty lines and quantile poverty lines. This is formally derived using the definition:

A poverty line $z$ is a mean poverty line if $z=\alpha \mu$ where $\mu$ is mean income and $\alpha>$ 0 ; a poverty line $z$ is a quantile poverty line if $z=\alpha \xi_{q}$ where $\xi_{q}$ is a quantile of order $q$, i.e., $\xi_{q}=\sup \{x \mid F(x) \leq q\}$. The sample estimate of $z=\alpha \mu$ is $\check{z}=\alpha \mathrm{x}$ with $x$ $=(1 / n) \sum_{i=1}^{n} x_{i}$; the sample estimate of $z=\alpha \xi_{q}$ is $\check{\mathrm{z}}=\alpha \mathrm{x}_{(r)}$ where $\mathrm{x}_{(r)}$ is the $r$ th order statistic of $\left(x_{1}, x_{2}, \ldots x_{n}\right)$ with $r=(n q)$. If $q=1 / 2, z$ is a median poverty line. 
From here, Zheng constructs an asymptotic covariance structure where the asymptotically nonparametric distribution-free statistical inference has been established. In determining the minimum sample size for the asymptotic theorem to be applicable, the Monte Carlo simulations with several parametric distributions were used. It was found out that 1000 was the sufficient value. Finally, this was further tested in stratified random samples and cluster samples.

\subsection{The Approach of Spatial Dimensions}

Kakwani and Hill (2002) improve the understanding of poverty and inequality by looking at the spatial dimensions of poverty. By integrating the economic theory of index numbers to spatial cost of living indices, they have developed a methodology to compare welfare levels of households situated in different regions within a country thereby making use of price indices to compare living costs. The methodology is as follows: first, the development of spatial costs of living and welfare indices in a two-region context; second, the use of natural axioms to derive the indices; and third, the application of the poverty index to a multilateral welfare and cost of living comparison across a country, in particular, Thailand. Instead of using axioms derived from observed prices and quantities (as what Diewert (1985) and Balk (1996) did), the authors derived their axioms from 
four cost functions. In developing the cost of living index (over time), a tworegion index for comparison is used. Regions $i$ and $j$ are represented by their utility level through $u_{i}$ and $u_{j}$, where a higher value in $u_{i}$ over $u_{j}$ would mean the welfare level in region $i$ is greater than $j$. The welfare of regions is given by $M_{i j}=$ $\mathrm{x}_{\mathrm{j}} / \mathrm{x}_{\mathrm{i}}$, where $\mathrm{x}_{\mathrm{i}}=e\left(u_{i}, \mathrm{p}_{i}\right)$ and $\mathrm{x}_{\mathrm{j}}=e\left(u_{j}, \mathrm{p}_{j}\right)$. The price vector is represented by $\mathrm{p}_{i}$ and $\mathrm{p}_{j}$. Since there is an assumption that the regions have different welfare levels, therefore $\mathrm{p}_{i} \neq \mathrm{p}_{j}$. The function that puts the effects of the differences in costs of living $\left(P_{i j}\right)$ and welfare levels $\left(S_{i j}\right)$ is:

$$
M_{i j}=f\left(P_{i j}, S_{i j}\right), \text { where } P_{i j}=P\left(u_{i}, u_{j}, \mathrm{p}_{i}, \mathrm{p}_{j}\right) \text { and } S_{i j}=\mathrm{S}\left(u_{i}, u_{j}, \mathrm{p}_{i}, \mathrm{p}_{j}\right)
$$

From this spatial cost of living function, nine axioms are derived. The cost of living index is given by $\log P_{i j}=\log e\left(u, \mathrm{p}_{j}\right)-\log e\left(u, \mathrm{p}_{i}\right)$, where $u$ is the utility level which can take many possible values $j i$ such as $u$ or $u$ or some average of the two. With 321 items of household consumption available in every region and the base set at 1992 prices, a multilateral regional comparison across regions in 1992, 1994, 1996 and 1998 shows that there is a wide regional disparity within Thailand with Northeastern Thailand being the poorest region. The paper also considered the effect of the 1997 Financial Crisis. It found out that per capita real income declined by $0.7 \%$ and urban areas, particularly Bangkok, were hardest hit by the crisis. The implication of this paper is that the redistribution policies of 
Thailand are inadequate, regressive and inequitable. Overall, Kakwani and Hill have contributed in poverty measurement by correcting the way the poor and nonpoor have been counted. By subjecting consumption index to the spatial living costs index, the conventional poor/non-poor dichotomy is refined to respond to measurement errors.

\subsection{Poverty, Psychological Resources and Subjective Well-Being}

The turn to subjective view on poverty can be indicated by the work of Lever et al. (2005). Here, the focus is to establish the effect of psychological factors in the relationship between poverty and well-being. Using nonprobabilistic, stratified sampling method, the authors used the following explanatory variables: strategies for coping with stress, competitiveness, mastery, locus of control, depression and self-esteem. In the literature, it is shown that there is a positive relationship between poverty and well-being; that is, the degree the population is impoverished, their well-being diminishes (Diener and BiswasDiener 2001; Easterlin 2001). However, others argued that the association between one's material life situation and subjective wellbeing is limited, affirming that a significant part of the variance of well-being is not directly explained by economic variables, but rather by psychological and social variables such as 
personality, aspirations, adaptation to the environment and motivation (Andrews and Withey 1976; Diener et al. 1995; Schyns 1998a in Diener and Biswas-Diener 2001; Benedikt 1999; Csikszentmihalyi 1999; Fuentes 2001; Csikszentmihalyi and Schneider, in press, in Csikszentmihalyi 1999). In this paper, the abovementioned psychological variables act as mediating factors in the structural model of explaining poverty and well-being. The conclusion from the model is that there are basically three routes or trajectories through which poverty impacts subjective well-being. First, there is a direct correlation showing that precarious life conditions have a negative impact on the perception of subjective well-being. The second trajectory illustrates that poverty has an impact on well-being through its influence from passive, evasive coping strategies, from an external locus of control and a lack of orientation toward competitiveness and mastery. Finally, a third trajectory presents itself when personal rejection (low self-esteem) and minimal orientation toward mastery are translated into depression, which directly impacts individuals' subjective perception of well-being (Lever et al. 2005: 402). 


\section{Conclusion}

Orshansky represented the U. S. Social Security position in the 1960's showing that there was works being done to fight against poverty.

Townsend and Sen would be the fundamental authors who would influence the Economics of Poverty for decades, leading the beginning of the incontestable dominance of the academia in the subject. Townsend redefined poverty as a relative phenomenon. Sen contributed with many and varied works, specially trying to explain the underlying mechanisms of poverty, to unite the better of the absolute and relative approaches and introducing the concepts of functioning on the basis of the capabilities approach.

In the meanwhile, methodological problems were raised due to data gathering mismatches with the theory and also because some theories were difficult to be applicable with the existing poverty indexes. Some important comments and contributions to the resolution of these problems were figured out in the turn to the twentieth-first century by Ravallion, Alkire, Atkinson and Pritchett.

The state-of-the-art in poverty measurement relies over the multidimensional approaches and other proposals in the economic literature and, sometimes, in interdisciplinary works between Economics and Psychology and 
Sociology. The Fuzzy Set Theory is largely employed to help Economics of Poverty to turn the Multidimensional Approach feasible since the seminal work of Cerioli and Zani. Other alternative approaches such as those using experimental experiences or others considering the level of psychological well-being as part of the poverty concept are sometimes irregular contributions that could be - as the multidimensional approach also - a path for economic research, sometimes with the collaboration of other social sciences, to the next decades. 


\section{References}

Alkire, Sabina, (2002). Valuing Freedoms: Sen's Capability Approach and Poverty Reduction. Oxford, Oxford University Press.

Andrews, F. M. and S. B. Withey, (1976). Social Indicators of Well-being: American's Perceptions of Life Quality. New York, Plenum Press.

Atkinson, A. B., (1985). "How should we measure poverty?", ESRC Programme on Taxation, Incentives and the Distribution of Income, Discussion Paper 82.

Atkinson, A. B., (1987). "On the Measurement of Poverty”, Econometrica 44 (4), 749-764.

Atkinson, A. B., (1998). Poverty in Europe. Oxford, Blackwell Publishers.

Atkinson, T., B. Cantillon, E. Marlier and B. Nolan, (2002). Social Indicators The EU and Social Inclusion. Oxford, Oxford University Press.

Balk, B.M., (1996). "A comparison of ten methods for multilateral international price and volume comparison." Journal of Official Statistics 12 (2), 199222.

Benedikt, M., (1999). Values. Austin, University of Texas Press.

Biewen, Martin, (2001). "Measuring the Effects of Socioeconomic Variables on the Income Distribution: An Application to the East German Transition Process", The Review of Economics and Statistics 83 (1), 185-190.

Bourguignon, François and Satya Chakravatry, (2003). "The Measurement of Multidimensional Poverty", Journal of Economic Inequality 1, 25-49.

Bourguignon, François and Gary Fields, (1990). "Poverty measures and antipoverty policy." Recherches Economique de Louvain 61 (3-4), 409427.

Bourguignon, François, Jaime de Melo and Christian Morrisson, (1991). "Poverty and Income Distribution during Adjustment: Issues and Evidence from the OECD Project." World Development 19 (11), 1485-1508.

Cashin, Paul, Paulo Mauro, and Ratna Sahay, (2001). "Macroeconomic Policies and Poverty Reduction: Some Cross-country Evidence." Finance and Development 38 (2), 46-49. 
Cerioli, Andrea and Sergio Zani, (1990). "A Fuzzy Approach to the Measurement of Poverty", in Income and Wealth Distribution, Inequality and Poverty. Berlin, Springer-Verlag, 272-84.

Cheli, Bruno and Achille Lemmi, (1995). "A 'Totally' Fuzzy and Relative Approach to the Multidimensional Analysis of Poverty", Economic Notes 24 (1), 115-134.

Clark, Stephen, Richard Hemming and David Ulph, (1981). "On Indices for the Measurement of Poverty." The Economic Journal 91 (362), 515-526.

Csikszentmilhalyi, M., (1999). "If we are so rich, why aren't we happy?" American Psychologist 44 (10), 821-827.

Deaton, Angus, (1997). The Analysis of Household Surveys: A Microeconometric Approach to Development Policy. Washington, The World Bank.

Deitz, Richard, (1996). “An Experiment in Income Redistribution and Poverty Measurement." Classroom Expernomics 5 (2).

Diener, E. and R. Biswas-Diener, (2001). "Will money increase subjective wellbeing?" Social Indicators Research 00, 1-51.

Diener, E., M. Diener and C. Diener, (1995). "Factors predicting the subjective wellbeing of nations." Journal of Personality and Social Psychology 69, $851-864$.

Diewert, W.E., (1985). "Microeconomic Approaches to the Theory of International Comparisons" (December 1985). NBER Working Paper No. T0053.

DiNardo, J., N. Fortin, and Th. Limieux, (1996). "Labour Market Institutions and the Distributions of Wages, 1973-1992: A Semiparametric Approach." Econometrica 65 (5), 1001-1044.

Dubnoff, Steven, (1985). "How much income is enough? Measuring public judgments." Public Opinion Quarterly 44, 285-99.

Easterlin, R., (2001). "Income and happiness: Toward a unified theory." The Economic Journal 101), 465-484.

Foster, J. E., (1984). “On Economic Poverty: A Survey of Aggregate Measures.” Advances in Econometrics 3, 215-251.

Foster, J., J. Greer, E. Thorbecke, (1984). "A class of decomposable poverty measures.” Econometrica 52, 761-765. 
Fuentes, N., (2001). "Economic theory and subjective well-being." Social Indicators Research 53 (3), 289-314.

Kakwani, Nanak and Robert Hill,, (2002), "Economic Theory of Spatial Cost of Living Indices with application to Thailand", Journal of Public Economics, 86, 71-97.

Kilpatrick, Robert W., "The income elasticity of the poverty line." Review of Economics and Statistics (1973), LV, pp. 327-32.

Laderchi, Caterina, Ruhi Saith, and Frances Stewart, (2003), "Does it Matter that we do not Agree on the Definition of Poverty? A Comparison of Four Approaches", Oxford Development Studies, 31 (3), 243-274.

Lever, Joaquina Palomar, Nuria Lanzagorta Piñor, and Jorge Hernandez Uralde, (2005), "Poverty, Psychological Resources and Subjective Well-being", Social Indicators Research, 73, 375-408.

Linsley, Colin and Christine Linsley, (1993), "Booth, Rowntree, and Llewelyn Smith: A Reassessment of Interwar Poverty", The Economic History Review, 46 (1), 88-104.

Moisio, Pasi, (2004), "A Latent Class Application to the Multidimensional Measurement of Poverty", Quality and Quantity, 38, 703-717.

Moisio, Pasi and Richard Breen, (2004), "Poverty dynamics corrected for measurement error", Journal of Economic Inequality, 2, 171-191.

Orshansky, Mollie, (1963), "Children of the Poor.” Social Security Bulletin, 26, 313.

Orshansky, Mollie, (1965), "Counting the Poor: Another Look at the Poverty Profile.” Social Security Bulletin, 28 (January): 3-29.

Pritchett, Lant, (2006), "Who is Not Poor? Dreaming of a World Truly Free of Poverty", The World Bank Research Observer, 21 (1), 1-23.

Qizilbash, Mozaffar, (2002), "A Note on the Measurement of Poverty and Vulnerability in the South African context", Journal of International Development, 14, 757-772.

Ravallion, Martin, (1996), "Issues in Measuring and Modelling Poverty." Economic Journal, 106 (438), 1328-1343.

Ravallion, Martin, (1998), Poverty Lines in Theory and Practice, LSMS Working Paper No. 133, Washington: World Bank Publications. 
Ravallion, Martin, (2003), The Debate on Globalization, Poverty and Inequality: Why Measurement Matters", World Bank Policy Research Working Paper, 3038.

Ravallion, Martin and Michael Lokshin, (2003), "On the Utility Consistency of Poverty Lines", World Bank Policy Research Working Paper, 3157.

Ravallion, Martin and Shaohua Chen, (1997), "What Can New Survey Data Tell Us about Recent Changes in Distribution and Poverty?" World Bank Economic Review, 11: 357-382.

Ravallion, Martin and Shaohua Chen, (2001), "How Did the World's Poorest Fare in the 1990s?", Review of Income and Wealth, 47 (3), 283-300.

Sen, Amartya K., (1976), "Poverty: An Ordinal Approach to Measurement", Econometrica, 46, 437-446.

Sen, Amartya K., (1979), "Issues in the Measurement of Poverty." Scandinavian Journal of Economics, 81(2), 285-307.

Sen, Amartya K., (1983), "Poor, Relatively Speaking." Oxford Economics Papers, 35, 153-169.

Sen, Amartya K., (1985), "A Sociological Approach to the Measurement of Poverty: A Reply to Professor Peter Townsend", Oxford Economic Papers, New Series, 37 (4), 669-676.

Townsend, Peter, (1979), Poverty in the United Kingdom: A Survey of Household Resources and Standards of Living, Berkeley: University of California Press.

Townsend, Peter, (1985), "A Sociological Approach to the Measurement of Poverty - A Rejoinder to Professor Amartya Sen", Oxford Economic Papers, New Series, 37 (4), 659-668.

Watts, H., (1968), “An economic definition of poverty”, in D.P. Moynihan, ed., On Understanding Poverty, New York: Basic Books.

World Bank, (1975), The Assault on World Poverty. Washington: World Bank.

World Bank, (1990), World Development Report 1990. Washington: World Bank.

Zheng, Buhong, (2001), "Statistical inference for poverty measures with relative poverty lines", Journal of Econometrics, 101, 337-356. 